\title{
Universal Time Dependence of Nighttime F Region Densities at High Latitudes
}

\author{
O. De la Beaujardière, ' v. B. Wick war, ${ }^{1}$ G. Caudal, ${ }^{2}$ J. M. Holt, ${ }^{3}$ J. D. Craven, ${ }^{4}$ \\ L. A. Frank, ${ }^{4}$ L. H. Brace, ${ }^{5}$ D. S. Evans, ${ }^{6}$ J. D. Winningham, ${ }^{7}$ and R. A. Heelis ${ }^{8}$
}

\begin{abstract}
Coordinated EISCAT, Chatanika, and Millstone Hill incoherent scatter radar observations have revealed that in the auroral zone, the nighttime $F$ region densities vary substantially with the longitude of the observing site: EISCAT's densities are the largest and Millstone Hill's are the lowest. The nighttime $F$ region densities measured by the individual radars are not uniform: the regions where the densities are maximum are the so-called "blobs" or "patches" that have been reported previously. The observations are consistent with the hypothesis that the nighttime densities are produced in significant amounts not by particle precipitation, but by solar EUV radiation, and that they have been transported across the polar cap. The observed differences can be explained by the offset of the geographic and geomagnetic poles. A larger portion of the magnetospheric convection pattern is sunlit when EISCAT is in the midnight sector than when Chatanika is. In winter, when Millstone Hill is in the midnight sector, almost all the auroral oval is in darkness. This universal time effect, which was observed on all coordinated three-radar experiments (September 1981 to February 1982), is illustrated using two periods of coincident radar and satellite observations: November 18-19, and December 15-16, 1981. These two periods were selected because they corresponded to relatively steady conditions. Dynamics Explorer (DE) measurements are used to aid in interpreting the radar observations. DE 1 auroral images show what portion of the oval was sunlit. DE 2 data are used to measure the ion drift across the polar cap. Because the altitude of the ionization peak was high, the decay time of the $\boldsymbol{F}$ region density was substantially longer than the transit time across the polar cap. The southward meridional wind that was observed coincidentally with the ionization patches at Chatanika and EISCAT contributed to the maintenance of the $F$ region by raising the altitude of the peak. DE 2 Langmuir probe measurements of electron density clearly showed a UT dependence, the same as that in the radar measurements.
\end{abstract}

\section{INTRODUCTION}

In the past years, several theoreticians have modeled the ionospheric densities in the polar regions. After the pioneering work of Knudsen [1974] and Knudsen et al. [1977], the effect of the displacement of the geographic and geomagnetic poles was introduced, and computer models were developed of increasing complexity and completeness [Watkins, 1978; Schunk and Raitt, 1980; Sojka et al., 1981, 1982; Schunk and Sojka, 1982; Sojka and Schunk, 1982]. The work of Schunk and co-workers has focused on showing how the combined effects of magnetospheric plasma convection and corotation about the geographic pole can be the cause of profound universal time (UT) variations. However, because of a lack of adequate measurements, very little has been done to verify these effects experimentally. During a short time period (September 1981 to February 1982), three incoherent scatter radars [Chatanika, Millstone Hill, and the European Incoherent Scatter facility (EISCAT)] could simultaneously probe the auroral zone from widely different longitudes. As part of project

\footnotetext{
ISRI International, Menlo Park, California.

${ }^{2}$ Centre de Recherche sur la Physique de l'Environnement, SaintMaur, France.

${ }^{3}$ Northeast Radio Observatory Corporation, Westford, Massachusetts.

${ }^{4}$ University of Iowa, lowa City.

sNational Aeronautics and Space Administration, Greenbelt, Maryland.

'National Oceanic and Atmospheric Administration, Boulder, Colorado.

${ }^{7}$ Southwest Research Institute, San Antonio, Texas.

'University of Texas at Dallas, Richardson, Texas.

Copyright 1985 by the American Geophysical Union.
}

Paper number 4A8291.

0148-0227/85/004A-8291\$05.00
MITHRAS (Magnetosphere-Ionosphere-Thermosphere Radar Studies) [de la Beaujardière et al., 1982, 1984], experiments were designed to take advantage of this opportunity, and now, for the first time, data have been acquired specifically to search for the predicted effects arising from the poles' offset.

Whereas many of the recent theoretical papers dealing with the effects of the pole displacement have focused on minima in the $F$ region ionization (mid-latitude trough or polar hole for example), in this paper we focus on nighttime ionization maxima. Coincident winter data for several periods were analyzed in search of longitudinal variations in the ionization maxima. Indeed, a dramatic UT effect was observed. The $F$ region density at night was larger at EISCAT than at Chatanika and was the smallest at Millstone's longitude.

Such enhancements in the $F$ region nighttime polar ionosphere have been reported previously from ionosonde data [for example, Sato and Rourke, 1964, and references therein]. More recently they have been observed with the Chatanika incoherent scatter radar [Vickrey et al., 1980], and with optical instruments [Weber et al., 1984]. These recent observations have shown that in the auroral zone and the polar cap, the enhancements are patchy in nature, with typical dimensions of the order of one to two hundred kilometers. They have been called "patches" or "blobs." Presumably, blobs, patches, and the enhancements described in this paper are the same thing, and we use these terms interchangeably. What we show here, is that detailed, simultaneous observations from three widely separated longitudes reveal that the peak density of these maxima strongly depends upon the longitude (or UT) of the observing site.

Note that the terms "density enhancement" or "density maxima" do not imply regions where somehow ionization was added to a background. In fact, it is probably more reasonable to assume that the background corresponds to the density maxima, a background that is eroded in an irregular way. In other words, the $F$ region 


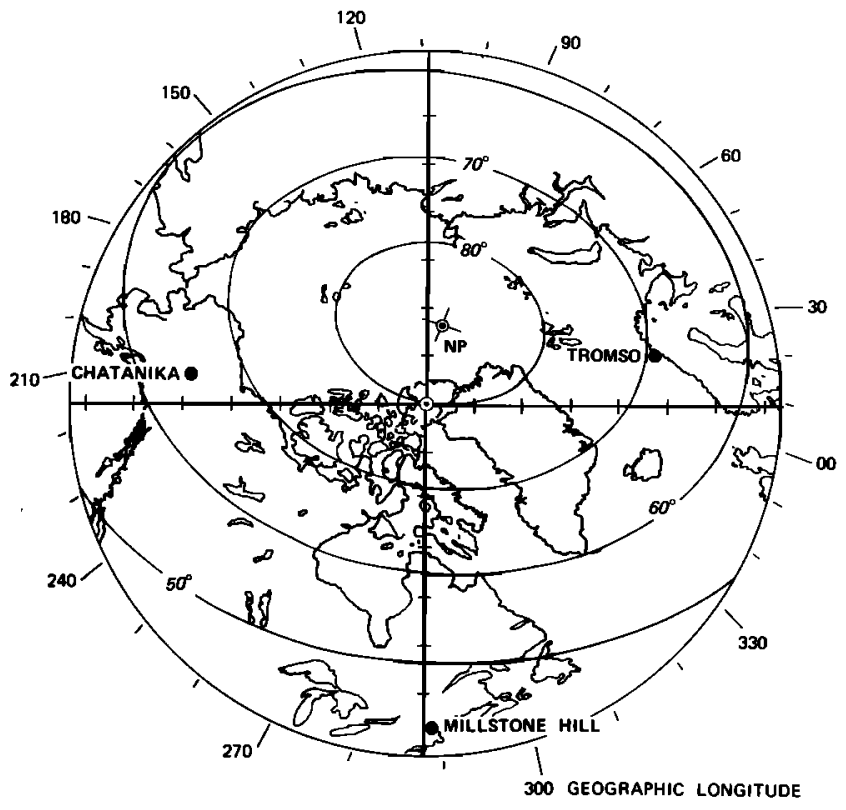

Fig. 1. Relative positions of the incoherent scatter facilities. The map is in geomagnetic coordinates with tick marks $5^{\circ}$ apart along two geomagnetic meridians. The north pole (NP) and ovals of constant geographic latitude are shown.

minima correspond to flux tubes where the ionization has decayed faster. It is beyond the scope of this paper to address the question of how a solar-produced ionization layer which presumably started as a smooth, sunlit $F$ layer, can evolve into blobs of a few hundred kilometer scale sizes.

Plasma transport across the polar cap has been recognized as very important in affecting the morphology of $F$ region densities [Sato and Rourke, 1964; Knudsen, 1974; Knudsen et al., 1977; Watkins, 1978; Sojka and Schunk, 1982; Foster, 1984; Kelly and Vickrey, 1984]. The recent work of Weber et al. [1984] was a clear experimental verification of the fact that the ionization maxima do move across the polar cap, driven in the generally antisunward direction by the $\mathbf{E} \times \mathbf{B}$ drift. This paper also emphasizes the role of plasma drift across the polar cap. Whereas the basic assumption of Kelley et al. [1982] was that the density enhancements are initially produced by soft particle precipitation, it is the assertion of this paper that these enhancements are initially produced by solar EUV radiation. We state that the observed UT variation in plasma densities can be explained by the relative position of the terminator and of the dayside portion of the auroral oval. This relative position changes with geographic longitude. Assuming that the $F$ region ionization observed in the auroral-zone midnight sector has originated near the cusp, the amount of solar illumination in the noon sector auroral zone will, to a first approximation, determine the amount of ionization in the night sector.

This paper is based on both satellite and radar data. Two specific periods of observation are described in detail. These periods were selected because the level of magnetic activity seemed to have been fairly constant during the observations. One period was magnetically quiet (December 15-16, 1981) and the other was moderately active but corresponded to fairly steady conditions (November 18-19, 1981). Although we will concentrate on these two intervals, the UT effect is observed in all the data available from three-radar coordinated experiments, irrespective of the general level of magnetic activity.

\section{EXPERIMENTAL Procedure}

The observations presented here were obtained as part of the MITHRAS campaign during which coordinated measurements in the auroral zone were conducted from the Chatanika, Millstone Hill, and EISCAT incoherent scatter radars. Measurements from space-borne and other ground-based instruments were also part of MITHRAS. A description of these observations can be found in the work by de la Beaujardiere et al. [1982, 1984]. The radar installations for Chatanika, Millstone, and EISCAT are described by Leadabrand et al. [1972], Evans et al. [1979], and Folkestad et al. [1983], respectively. Figure 1 shows the locations of the incoherent scatter facilities. The map is in geomagnetic coordinates, and includes curves of constant geographic latitude. The three radars are equally spaced around 14 hours of magnetic local time, with Millstone trailing EISCAT by 7 hours and leading Chatanika by 7 hours. The EISCAT transmitter is located at Tromso. Both Cha-

TABLE 1. Coordinated Three-Radar Observations, 1981 and 1982

\begin{tabular}{|c|c|c|c|c|c|c|c|}
\hline \multicolumn{2}{|c|}{ Chatanika } & \multicolumn{2}{|c|}{ Millstone Hill } & \multicolumn{2}{|c|}{ EISCAT } & \multicolumn{2}{|c|}{ Mode } \\
\hline Start & End & Start & End & Start & End & $\begin{array}{l}\text { Chatanika } \\
\text { and Millstone }\end{array}$ & EISCAT \\
\hline Sep. 30, 0I30 & Oct. 1,0138 & Sep. 29, 1949 & Oct. 1,0346 & Sep. 30,1130 & Oct. 1,0900 & MITHRAS 2 & $\mathrm{CP}(-1)$ \\
\hline Oct. 7, 0011 & Oct. 8,1214 & Oct. 7, 2236 & Oct. 8,2400 & Oct. 6, 2200 & Oct. 7,2120 & MITHRAS 3 & $\mathrm{CP}(-1)$ \\
\hline Oct. 25,0031 & Oct. 26,2400 & Oct. 24, 0217 & Oct. 26,1328 & Oct. 25,1630 & Oct. 26,0900 & MITHRAS 1 & $\mathrm{CP}(0)$ \\
\hline Oct. 18,0017 & Nov. 18,2400 & Nov. 17,2124 & Nov. 19,0500 & Nov. 18,0900 & Nov. 19,0900 & MITHRAS 2 & $\mathrm{CP}(0)$ \\
\hline Dec. 8,2143 & Dec. 9,2400 & Dec. 8,2235 & Dec 9, 0456 & Dec. 8,1500 & Dec. 9,2020 & MITHRAS 3 & $\mathrm{CP}(-3 \mathrm{e})$ \\
\hline Dec. 15, 2241 & Dec. 17,0010 & Dec. 15,2146 & Dec. 17,0449 & Dec. 15,1500 & Dec. 16,1940 & MITHRAS 2 & $\mathrm{CP}(-3 \mathrm{~s})$ \\
\hline Jan. 26,1818 & Jan. 29,0129 & Jan. 26,2121 & Jan. 28,0129 & Jan. 26,1500 & Jan. 27,2300 & MITHRAS 3 & $\mathrm{CP}(3)$ \\
\hline
\end{tabular}

Times and dates are in UT. 


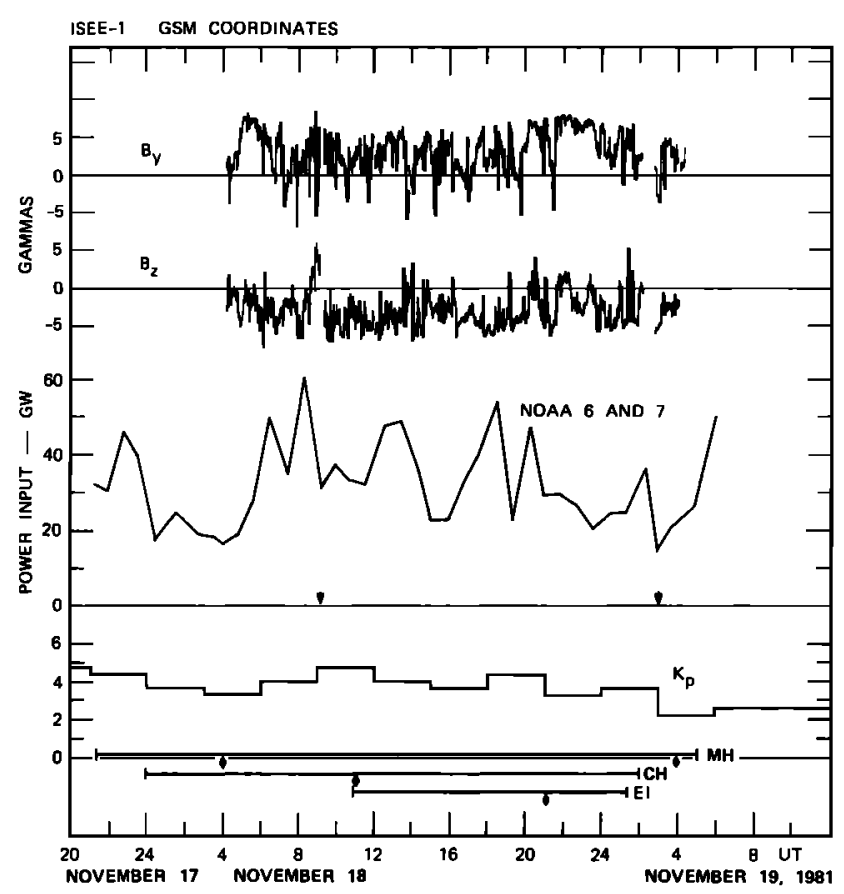

Fig. 2. Overview of the geomagnetic conditions on November 18-19, 1981, as a function of UT: IMF $B_{z}$ and $B_{y}$ components; hemispheric power input, $K p$. The times at which the radars were operated are also indicated. The diamonds point to the UT when each radar is at magnetic midnight, and the arrows to the times of the DE 1 images shown in Plate 2.

tanika and EISCAT lie within the nightside auroral oval, at invariant latitudes of $65.1^{\circ}$ and $66.3^{\circ}$, respectively. Millstone Hill is south of the auroral zone but makes high-latitude measurements by pointing north at low elevation angles. The geographic latitudes and longitudes of Chatanika, Tromso, and Millstone Hill, respectively, are $\left(65.1^{\circ},-147.5^{\circ}\right),\left(69.5^{\circ}, 19.2^{\circ}\right)$, and $\left(42.6^{\circ},-71.5^{\circ}\right)$.

The days when data from all three radars were available are listed in Table 1. A variety of operating modes was used, as indicated by the EISCAT Common Program (CP) mode number and by the MITHRAS mode number. The details of these modes are given in the papers by de la Beaujardiere et al. [1982, 1984] and Folkestad et al. [1983]. It suffices here to say that the MITHRAS 1 mode affords the largest latitudinal coverage, whereas the MITHRAS 2 mode provides a local measurement, but with a better time resolution. MITHRAS 3 is intermediate in latitudinal coverage and time resolution.
During the November 18-19 and the December 15-16 experiments the radars were operated in the MITHRAS 2 mode. In this mode, the Chatanika and EISCAT radars measured the local ionospheric parameters as a function of height and time. During the November experiment, the EISCAT antennas were fixed, and during the December one they were cycled through three positions. The Millstone Hill radar pointed obliquely at two azimuths straddling the magnetic meridian $\left(11^{\circ}\right.$ and $\left.341^{\circ}\right)$; at each azimuth, the radar elevation varied from $4^{\circ}$ to $18^{\circ}$ by $2^{\circ}$ steps.

Concurrent satellite data shown include (1) interplanetary magnetic field (IMF) components from ISEE 1 and 3 (provided by E. J. Smith, J. Berchem, and C. T. Russell), (2) total particle energy deposited into one hemisphere estimated from NOAA 6 and 7 [ Hill et al., 1982], (3) auroral images from the spin-scan auroral imaging instrument (SAI) on board Dynamics Explorer 1 (DE 1) [Franket $a l ., 1981$ ], and (4) one component of the ionospheric electric field from the ion drift meter (IDM) [Heelis et al., 1981], electron energy spectra from the low-altitude plasma instrument (LAPI) [Winningham et al., 1981], and electron density from the Langmuir probe [Krehbiel et al., 1981], all on board the DE 2 satellite. The instruments on DE 1 and 2 are described in a special issue of Space Science Instrumentation [Hoffman and Schmerling, 1981]. During the November-December period considered here, the coplanar orbits of the two DE satellites were located near the dawn-dusk plane.

\section{November 18-19, 1981: AN ACtive Period}

\section{Overall Conditions}

The first example corresponds to a period of moderate magnetic conditions. The overall conditions are summarized in Figure 2 using the IMF $B_{y}$ and $B_{z}$ components from ISEE 1 in GSM coordinates, the NOAA 6 and 7 hemispheric power input, and the $K p$ index. The hemispheric power input that is plotted is the average of two consecutive NOAA 6 and NOAA 7 individual power measurements. Care was taken in this average to use one value from the northern hemisphere and one from the southern hemisphere, in order to minimize possible bias arising from different detectors and from differing geometries in the auroral zone crossings. $K p$ remained between 3 and 5 during the interval considered. The power input by particle precipitation was high, above $20 \mathrm{GW}$ for most of the time, and fairly constant, which is indicative of a prolonged period of moderate activity. (The power input did not vary by more than a factor of $\sim 3$.) The IMF was also fairly

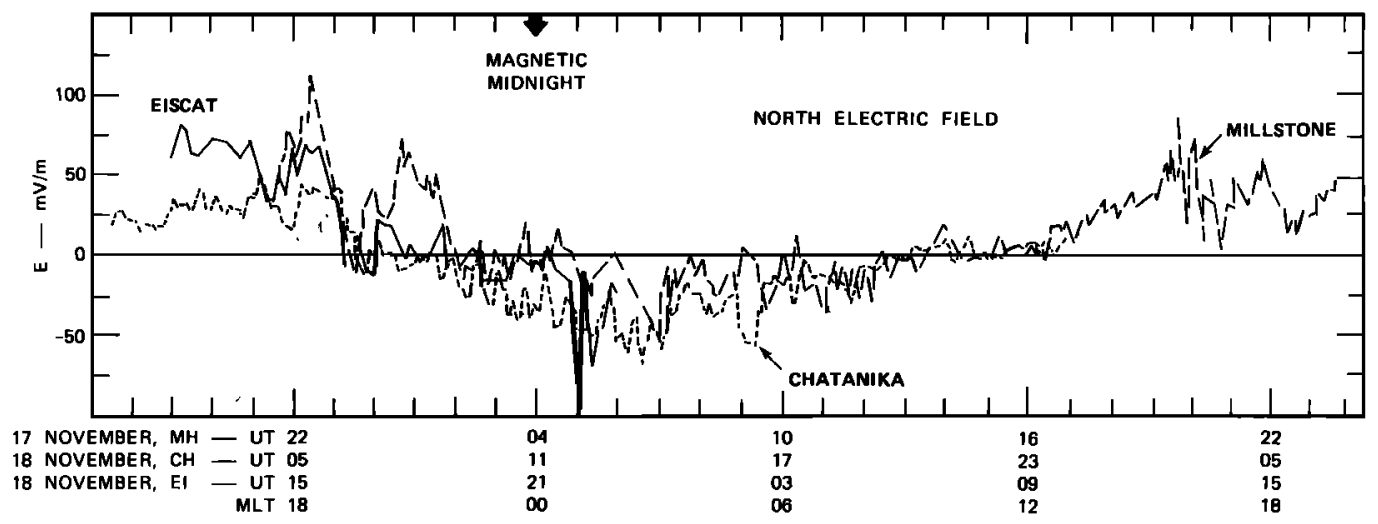

Fig. 3. Electric field (northward component) measured by the three radars, as a function of MLT. The corresponding UT's for each radar are also shown (November 17-19, 1981). 


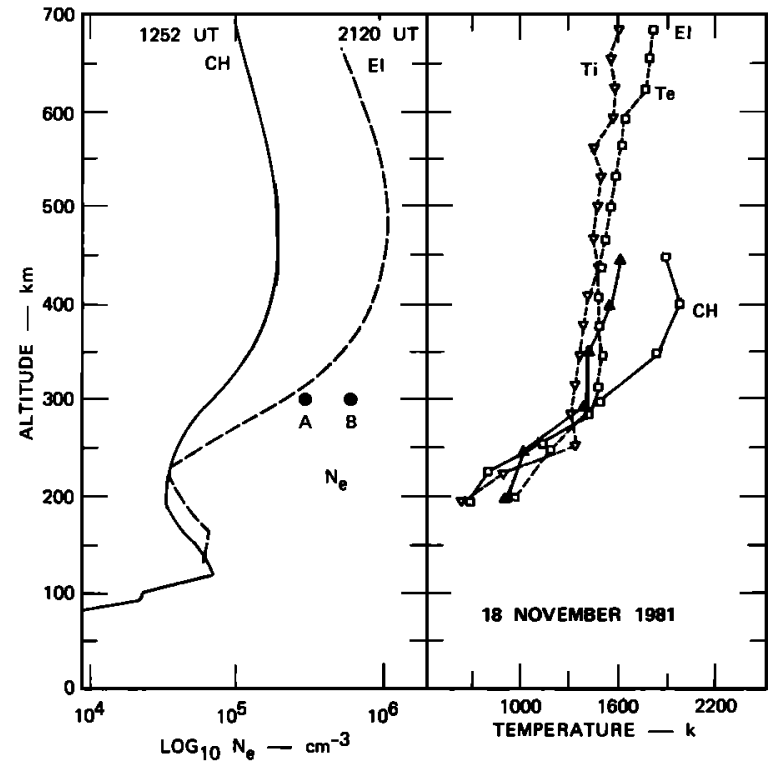

Fig. 4. Altitude profiles of electron density, ion temperature (triangles) and electron temperature (squares) within density maxima at Chatanika and EISCAT (November 18, 1981). The Points A and B correspond to the theoretical values calculated by Sojka and Schunk [1982] in the midnight sector for Millstone and Chatanika (A), and for EISCAT (B).

steady during the observation period; the $B_{z}$ component was negative, averaging $\sim-5 \gamma$, and the $B_{y}$ component was $\sim+3 \gamma$.

Caudal et al. [1984] have examined the electric field variations detected with the three radars, in an effort to describe the largescale convection pattern during this period. Figure 3 shows the electric field northward component measured by the three radars and plotted as a function of MLT. The UT of the measurement at each radar site is also indicated. Magnetic midnight is marked by a thick arrow on the top of the figure. As previously mentioned, EISCAT and Chatanika are almost at the same invariant latitude. For Millstone, the electric field shown is that measured at approximately the same invariant latitude, $65^{\circ}$. It is clear from Figure 3 and from Figure 2 of Caudal et al. [1984] that the ion convection patterns observed from the three sites are quite similar at a fixed invariant latitude. These authors showed that specific features in the convection appear in the observations from each of the radars. For example, in the noon sector, very intense electric fields are present at quite low latitudes; in the midnight sector there is a wide range of local time where the measured convection is very small. Caudal et al. [1984] concluded that the large-scale convection appeared to be close to a steady state during the observing period.

Therefore the overall magnetic activity, the particle energy input, and the large-scale convection remained reasonably steady during the November 18-19 MITHRAS experiment. Thus, when comparing the $F$ region for similar MLT's we can assume with some confidence that the effects on the ionosphere of the electric field and particle precipitation were similar at the three longitudes. Under this assumption, differing behaviors in the ionospheric $F$ region density cannot be attributed to temporal variations in the magnetospheric convection and precipitation.

\section{F Region Nighttime Ionosphere}

Plate 1 shows electron densities in a pseudocolor format as a function of altitude, UT, and local time for Millstone, Chatanika, and EISCAT for the November and December experiments. The teardrop-shaped maximum in the middle of Plate $1 a$ is the daytime ionization observed from Millstone. The curious shape of this maximum is partly due to the fact that the radar elevation angle was low $\left(12^{\circ}\right)$ and that a range of latitudes was sampled along the radar line of sight. The daytime maximum reached about $1.5 \times 10^{6}$ $\mathrm{el} / \mathrm{cm}^{3}$. On either side, the nighttime ionization maximum was $\simeq 1$ $\times 10^{5} \mathrm{el} / \mathrm{cm}^{3}$.

For the Chatanika observations, the daytime hours correspond to the left and right sides of Plate $1 b$. The daytime densities were almost the same at the Millstone and Chatanika longitudes, but the nighttime densities were a factor of $\sim 3$ greater at Chatanika (i.e., of the order of $3 \times 10^{5} \mathrm{el} / \mathrm{cm}^{3}$ ). At EISCAT, the nighttime densities, depicted in the center of Plate $1 c$, were even larger, exceeding $10^{6}$ $\mathrm{el} / \mathrm{cm}^{3}$ at $2120 \mathrm{UT}$. They remained very large for several hours, from $\sim 1800$ to 2200 UT ( 2100 to 0100 MLT).

The density enhancements appear fairly patchy at Chatanika and EISCAT (Plates $1 b$ and $1 c$ ). During this particular experiment, the radar operating modes were not designed to study the structure of these density maxima. However, during other MITHRAS experiments the Chatanika radar was scanned in elevation (modes 1 and 3 in Table 1). At night, when these other modes were used, the radar data showed that these $F$ region enhancements were indeed the same as the blobs described by Vickrey et al. [1980].

Typical density profiles through ionization maxima are plotted in Figure 4 for Chatanika and EISCAT. Note that the peak of the layer was quite high within the blobs: $475 \mathrm{~km}$ altitude for EISCAT and $425 \mathrm{~km}$ for Chatanika. The profiles of electron and ion temperatures are also shown in Figure 4. At Chatanika, the electrons and ions were not quite in thermal equilibrium, indicating that some energy was being deposited in the electron gas, presum-

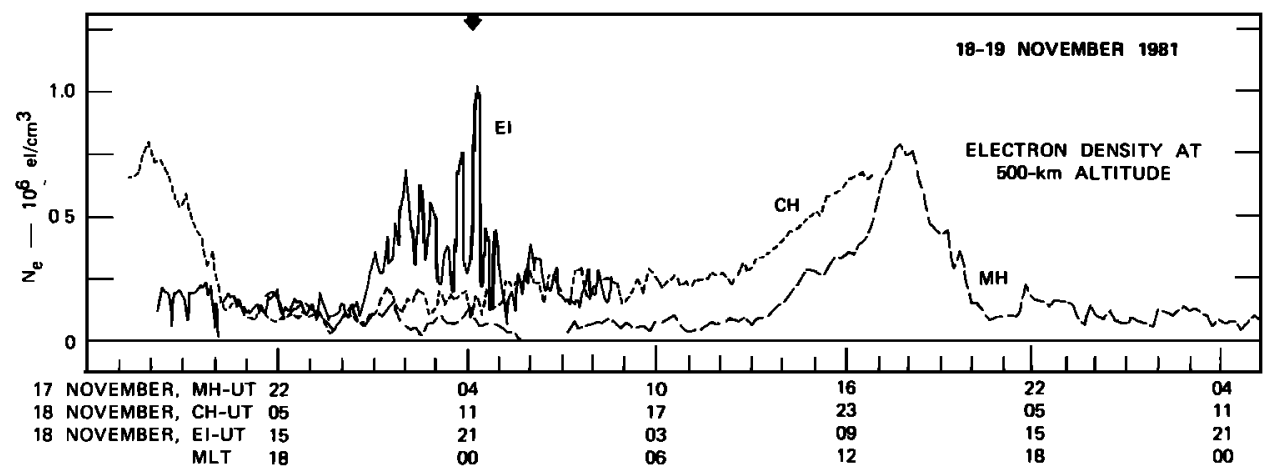

Fig. 5. Electron density at $500 \mathrm{~km}$ altitude measured from Millstone, Chatanika, and EISCAT as a function of MLT. The bottom scales indicate the corresponding UT at each site (November 17-19, 1981). 


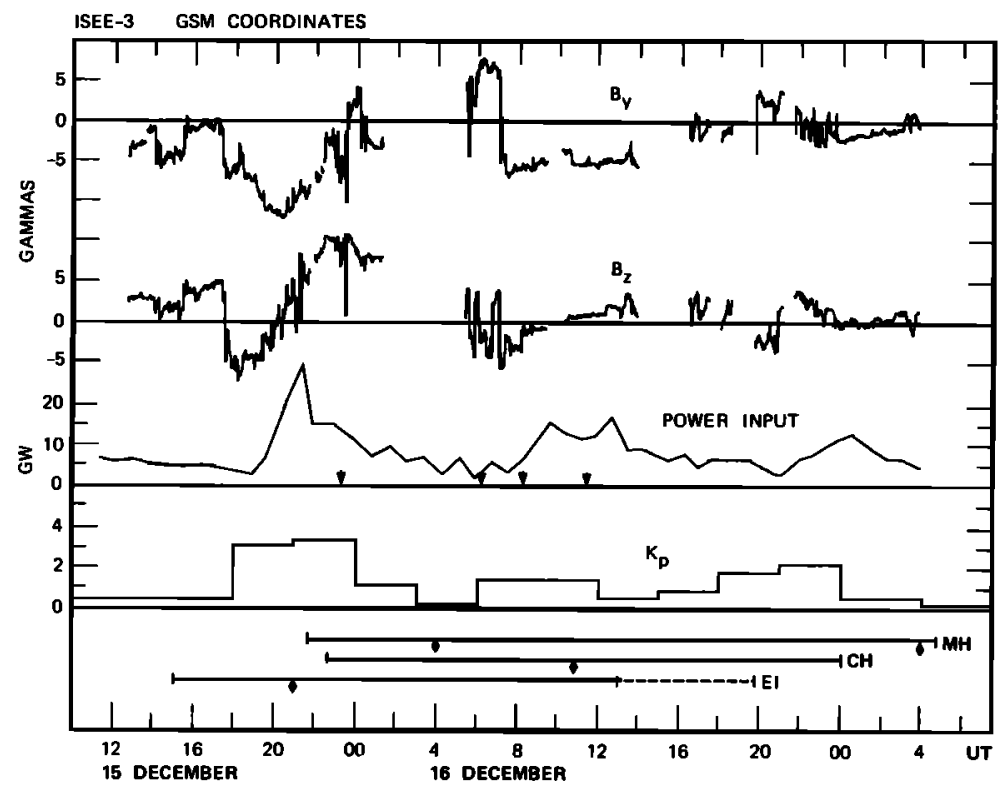

Fig. 6. Same as Figure 2 but for December 15-16, 1981. In the upper panel, the UT has not been shifted to account for the propagation time from ISEE 3 to the magnetosphere $(\simeq 1.5$ hours).

ably from soft particle precipitation. Calculations of the energy deposited in the $F$ region were performed using the energy balance equations for the electrons, as described by Kofman and Wickwar [1984]. The energy deposited in the electrons, integrated over all $F$ region heights, only reached about $2 \times 10^{7} \mathrm{keV} \mathrm{cm}^{-2} \mathrm{~s}^{-1}$ at the time that corresponds to the Chatanika profile of Figure 4; the nighttime average was $\sim 0.5 \times 10^{7} \mathrm{keV} \mathrm{cm}^{-2} \mathrm{~s}^{-1}$. These fluxes are not sufficient to produce any appreciable ionization above $300 \mathrm{~km}$ [Roble and Rees, 1977; Mantas and Walker, 1976]. Therefore, the high-density plasma at both Chatanika and EISCAT must have been convected to the radar, rather than locally produced.

Figure 5 is a synopsis of the $F$ region measurements for November $18-19,1981$. The $500-\mathrm{km}$ altitude ion density from the three radars is displayed as a function of MLT using the same format as in Figure 3. The $500-\mathrm{km}$ level was selected because at this altitude the Millstone beam intersected an invariant latitude close to that of EISCAT and Chatanika. Magnetic midnight is to the left of center in the figure. The figure clearly shows that the nighttime density was the largest at EISCAT, and the smallest at Millstone.

\section{December 15-16, 1981: A Quiet Period}

\section{Overall Conditions}

The second example corresponds to relatively quiet magnetic conditions, as illustrated in Figure 6. The IMF $B_{z}$ component from ISEE 3 was positive, and $K p$ remained less than 2 during most of the period. The hemispheric power input was below $10 \mathrm{GW}$ except during three intervals. Even then, it only once reached the 20-GW level, which was among the lowest values for the November 18 experiment. The magnetograms from College (very close to Chatanika) and Tromso confirm that the period was very quiet.

While both Chatanika and EISCAT were operating, two small magnetic disturbances occurred, one at $\simeq 2000$ UT on December 15 , the other at $\simeq 0830$ UT on December 16 . For brevity, we refer to these as substorms in the remainder of the paper. Both occurred shortly after two brief intervals of southward $B_{z}$ (Figure 6) and were presumably triggered by these changes in the IMF direction. It is during these two periods that the hemispheric power input maximized. At the radar latitudes the magnetic and electric field signatures of these two substorms were small, and we can still state that the overall conditions remained relatively quiet and fairly steady during the period of observation. Available sequences of DE 1 auroral images during $\sim 15$ hours of this period support this conclusion.

\section{F Region Nighttime Ionosphere}

$F$ region electron concentrations are shown as functions of altitude, UT, and local time in Plates $1 d$, le, and $1 f$, for Millstone, Chatanika, and EISCAT, respectively. As was the case on November 18 , the $F$ region density was very small at Millstone during the night (daytime ionization is seen on the left edge and near the middle of Plate $1 \mathrm{f}$ ). In contrast, intense density maxima were detected at Chatanika and EISCAT (around 1400 and 2300

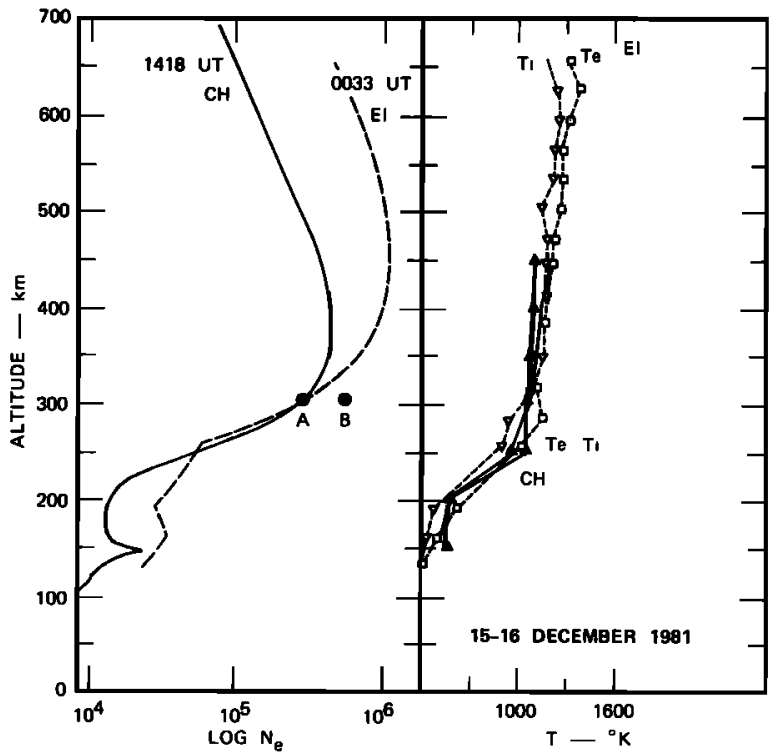

Fig. 7. Same as Figure 4, but for December 15-16, 1981. 


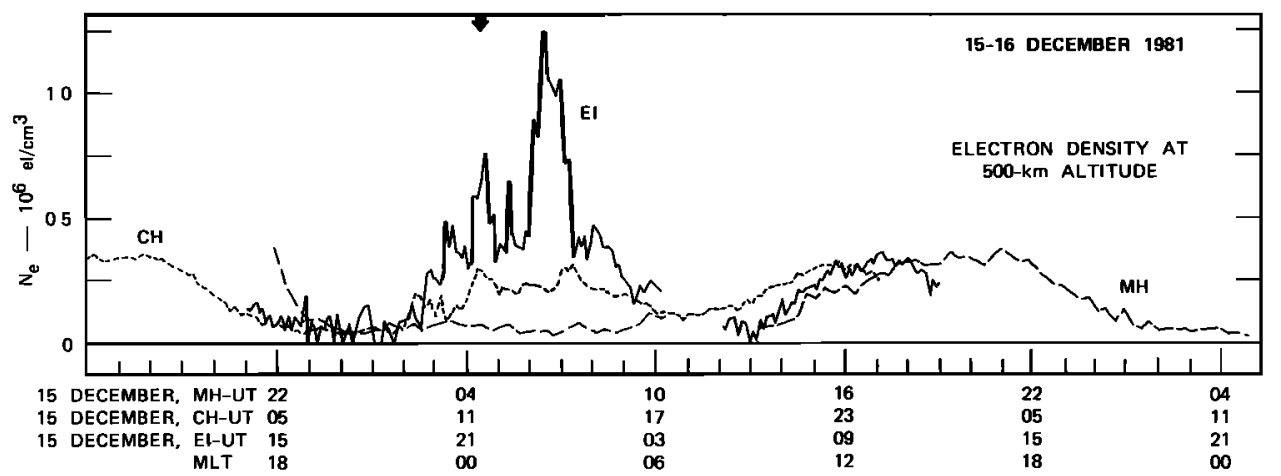

Fig. 8. Same as Figure 5, but for December 15-16, 1981.

UT, respectively). These maxima were more pronounced than on November 18-19.

Individual profiles, shown in Figure 7, indicate that the height of the $F$ layer was 360 and $430 \mathrm{~km}$, respectively, for Chatanika and EISCAT. The ion and electron temperatures were nearly equal on this day, indicating that the electron gas was in approximate thermal equilibrium with the neutrals, and that virtually no soft precipitation was taking place coincidentally with the observations. As was concluded for the previous example, the high-density plasma must have been convected into the radar field of view, rather than locally produced.

A summary of the electron density observations at the $500-\mathrm{km}$ altitude level is shown in Figure 8. This plot shows that the $500-\mathrm{km}$ altitude electron densities at EISCAT were larger during the night than during the day. This may be due to the greater altitude of the layer during the night. The longitudinal effect in the nighttime density is again present, with the patches of ionization most intense at EISCAT, smaller, but still intense at Chatanika, and nonexistent at Millstone Hill's longitude.

\section{Other Colncident Auroral Zone ObServations}

The cases of November 18-19 and December 15-16, 1981, reported here are not isolated. Data from MITHRAS experiments obtained on other days have been examined (Table 1), and, in all cases but one, the nighttime ion density at EISCAT was larger than at Chatanika, which in turn was larger than that at the longitude of Millstone Hill. This one exception, during which the density at EISCAT was barely larger than at Chatanika, is discussed in a later section.

Also, decades of ionosonde measurements in the Scandinavian
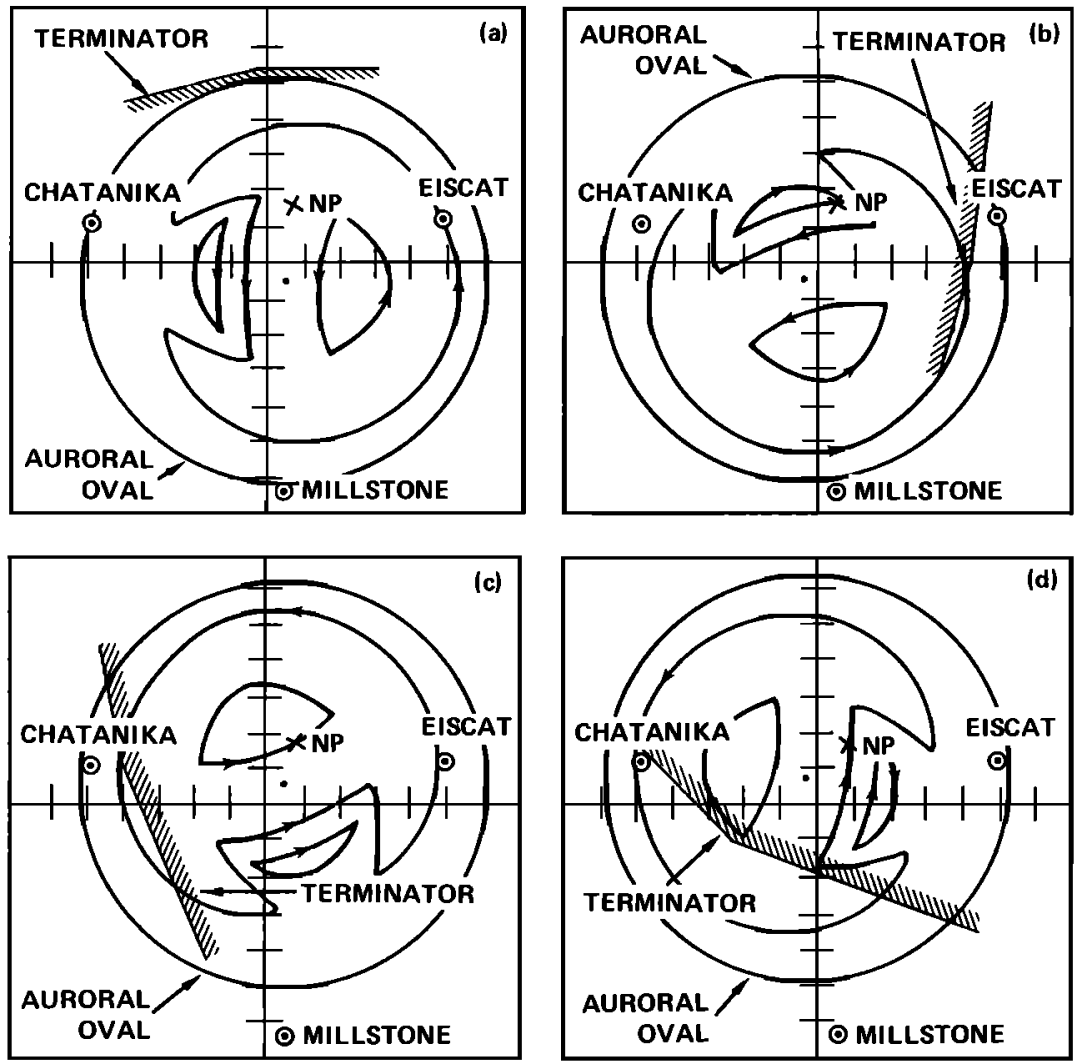

Fig. 9. Maps, in geomagnetic coordinates, showing the relative position of the auroral oval and ground terminator when (a) Millstone, $(b)$ Chatanika, and (c) EISCAT are in the midnight sector; Figure $9 d$ is for UT $=1800$. 
sector have revealed that a significant maximum in nighttime density is virtually always present (T. Turunen, private communication, 1984). These observations seem to confirm that the UT effect is not accidental.

\section{INTERPRETATION OF RADAR DATA AND Corroborative Evidence}

\section{Position of the Terminator Relative to the Auroral Zone}

The interpretation advanced here is that the high-density plasmas observed at night at Chatanika and EISCAT were not locally produced but were produced by EUV insolation within the dayside convection region, and convected across the polar cap [Sojka and Schunk, 1982; Foster, 1984; Weber et al., 1984; Kelly and Vickrey, 1984]. The recent empirical models giving the auroral oval boundaries, such as the models of Gussenhoven et al. [1981, 1983], can be used to pursue this idea further. The maps of Figures $9 a-9 c$ show the position of the equatorward boundary of the diffuse auroral oval at the three universal times when each station was at midnight. (For clarity, the coastlines shown on Figure 1 are not repeated.) The invariant latitude of this boundary is that statistically determined by Gussenhoven et al. [1983]; we have drawn the boundary corresponding to $K p=3$, the lowest value of $K p$ during most of the November 18 period under consideration. As a guide, a simple two-cell convection pattern is sketched on each map. This pattern is that of Sojka et al. [1979] and is in the noncorotating frame of reference. The position of the noon terminator is also shown, i.e., where the solar zenith angle (SZA) is $90^{\circ}$. Although somewhat arbitrary, the $90^{\circ}$ value was chosen because it corresponds to a grazing incidence for which EUV production is reduced. However, $F$ region ionization can occur for SZA up to about $105^{\circ}$. When Millstone is at midnight, the entire auroral oval is in darkness (Figure $9 a$ ). When Chatanika is at midnight, only part of the auroral oval is sunlit (Figure $9 b$ ). Finally, when EISCAT is at midnight, a larger fraction of the dayside auroral oval is sunlit (Figure 9c). The last map (Figure $9 d$ ) is for $1800 \mathrm{UT}$; around this time, the insolation of the auroral zone is the largest. Thus, plasma convected across the polar cap carries a greater ionization density when EISCAT and western Siberia are in the midnight sector than when Chatanika or Millstone Hill are.

Sequences of DE I auroral images are available for the observing periods discussed here, enabling us to provide specific examples of the relative locations of the radar sites, the instantaneous auroral oval, and the terminator. Six auroral images from these sequences are displayed in Plates $2 a-2 f$. The UT's of the images are indicated on the upper left corner of each panel, and marked by arrows in Figures 2 and 6 . They have been selected to demonstrate relative locations when each of the three radars is near the midnight sector. The images display the distribution of auroral emissions in the northern polar region and atmospheric dayglow in the sunlit hemisphere arising principally from atomic oxygen at about 130.4 and $135.6 \mathrm{~nm}$. The sensitivity passband for the images is $123-155 \mathrm{~nm}$. The terminator $\left(\mathrm{SZA}=90^{\circ}\right.$ ) and limb at the earth's surface are superposed on each image for reference. EISCAT, Chatanika, and Millstone are at the center of the circles which are the $400-\mathrm{km}$ intercept of the cones at $58^{\circ}, 35^{\circ}$, and $12^{\circ}$ elevation, respectively. Thus, the diameter of the circle is greatest for Millstone Hill and smallest for EISCAT, and these circles roughly match the radars' field of view.

Two images from the November 18-19 observation period are presented to demonstrate several key points. The image of 0906 UT on November 18 (Plate $2 a$ ) displays the northern auroral oval at a time when Chatanika is close to magnetic midnight ( $M L T=2200$ ). EISCAT and the equatorward edge of the aurora in the noon sector are sunlit. The image from 0322 UT on November 19 (Plate $2 b$ ) displays an auroral oval located entirely within the dark hemisphete as Millstone $\mathrm{H}_{1} l \mathrm{l}$ is close to local midnight (MLT = 2330). Images taken on the previous day (November 18, not shown here) demonstrate again that the entire auroral oval was in the dark hemisphere when Millstone was in the midnight sector. No image was taken of the northern polar region when EISCAT was in the midnight sector. However, the photographs that correspond to the closest time available ( 1620 UT on November 18 , not shown here) do indicate that a large portion of the oval was sunlit.

Four auroral images are presented in Plates $2 c-2 f$ to supplement the observations of December 15-16, 1981. On December 15 at 2313 UT (Plate $2 c$ ), EISCAT was very close to magnetic midnight $(M L T \simeq 0200)$. At this time, as well as several hours before, the noon sector of the oval was partly sunlit. Maximum separation between the terminator and the auroral oval is observed $\sim 7$ hours later at 0558 UT (Plate $2 d$ ) in a period of minimum auroral activity (see Figure 6). Auroral intensities were generally weak, $\lesssim 1 \mathrm{kR}$ at 130.4 and $135.6 \mathrm{~nm}$ around the auroral oval at this time. By 0812 UT the auroral oval had expanded to more typical dimensions, and more intense diffuse emissions were present over Chatanika in the premidnight sector (Plate $2 e$ ). A narrow auroral oval remained separated from the terminator in the local noon sector. The last image (Plate $2 f$ ) shows that at 1126 UT, when Chatanika was at magnetıc midnight, part of the oval was sunlit.

A comparison between the two images shown in Plates $2 d$ and $2 e$ and those of Plates $2 a$ and $2 b$ illustrates clearly that in the December 16 observations the separation between the terminator and the auroral oval was larger than in the November 18 observations. Two factors contributed by an equivalent amount $\left(\sim 4^{\circ}\right)$ to this separation: (1) on December $15, K p$ was small, and thus the radius of the oval is expected to be smaller; and (2) the date is closer to winter solstice, and thus the terminator was further south.

These DE 1 auroral images confirm the conclusions drawn from Figure 9 in which a statistical model was used to infer the position of the auroral zone. A larger portion of the auroral oval is sunlit when it is midnight at EISCAT rather than when it is midnight at Chatanıka or Millstone. Depending upon the season and the activity, most or all of the auroral oval is in darkness when Millstone is in the midnight sector.

We saw that the $F$ region nighttime ionization depends critically on the geographic latitude of the noon auroral oval. This latitude changes both with magnetic activity and with longitude (or UT). Of these two factors, the longitudinal effect is the largest; for a given $K p$, the geographic latıtude of this boundary varies with UT by about $18^{\circ}$; whereas this latitude varies by only $6^{\circ}$ if $K p$ changes from 0 to 5 [Gussenhoven et al., 1983].

Obviously, it is the position of the overall plasma convection pattern that is important, not the position of the diffuse auroral oval precipitation. However, to a first approximation, the diffuse aurora is located within the region of sunward return flow, while the polar cap and the discrete aurora at the poleward edge of the oval are located within the region of antisunward flow [Torbert et al., 1981; Heelis et al., 1980]. This statistical result was confirmed by actual DE 2 measurements from the LAPI and the plasma drift instruments. As an example, Plate 3 shows the Langmuir probe, the drift meter, and the LAPI data for November 18 (orbit 1586) and December 16 (orbit 1998). On both dawnside and duskside, the electric field equatorward edge is at the same or at a slightly 

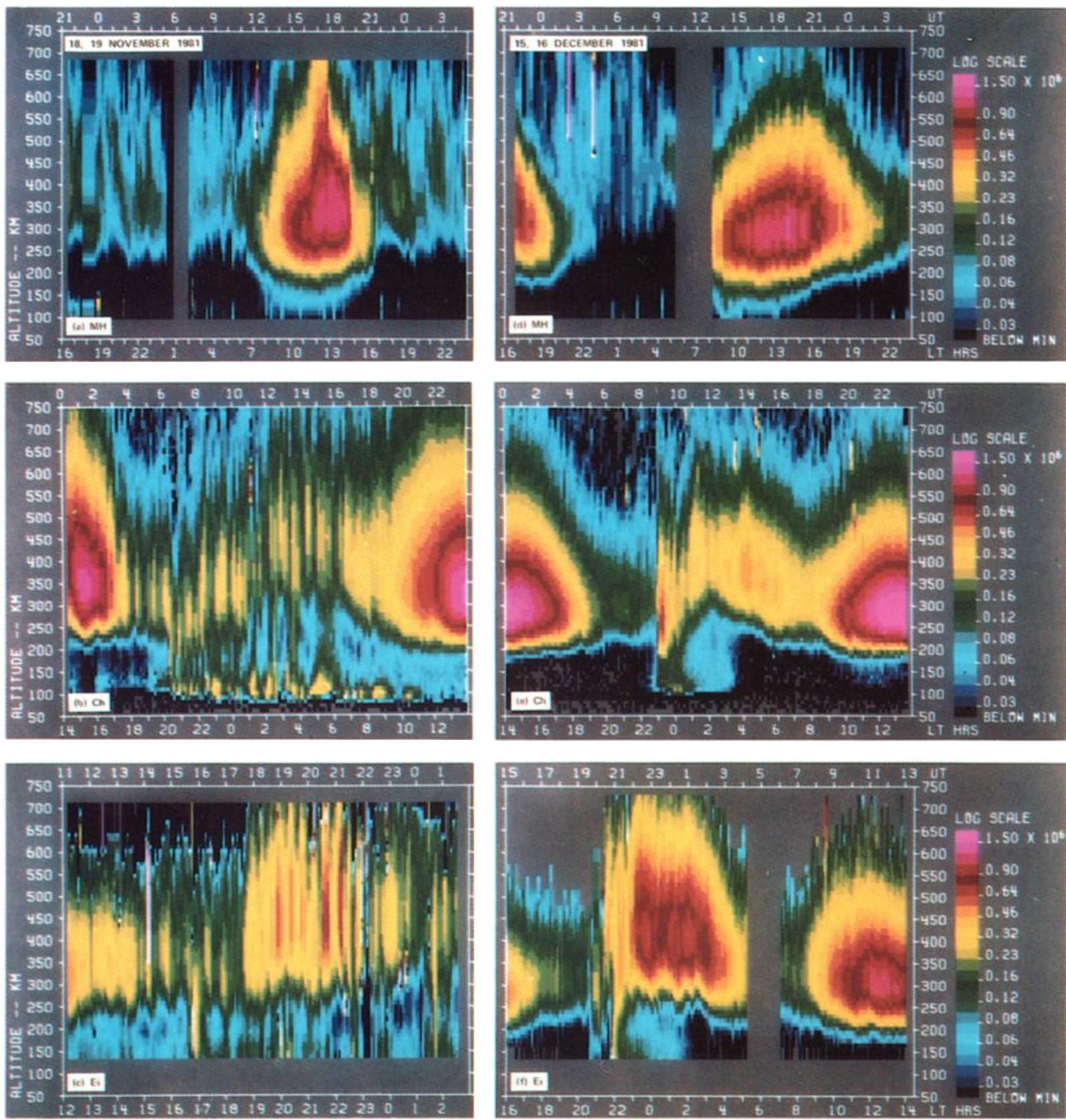

Plate 1 Electron density plotted in a pseudocolor format as a function of time and altitude on November 17-19, 1981, for (a) Milstone Hill, (b) Chatanika, and (c) EISCAT; and on December 15 16, 1981, for (d) Millstone Hill, (e) Chatanika, and $(f)$ EISCAT 

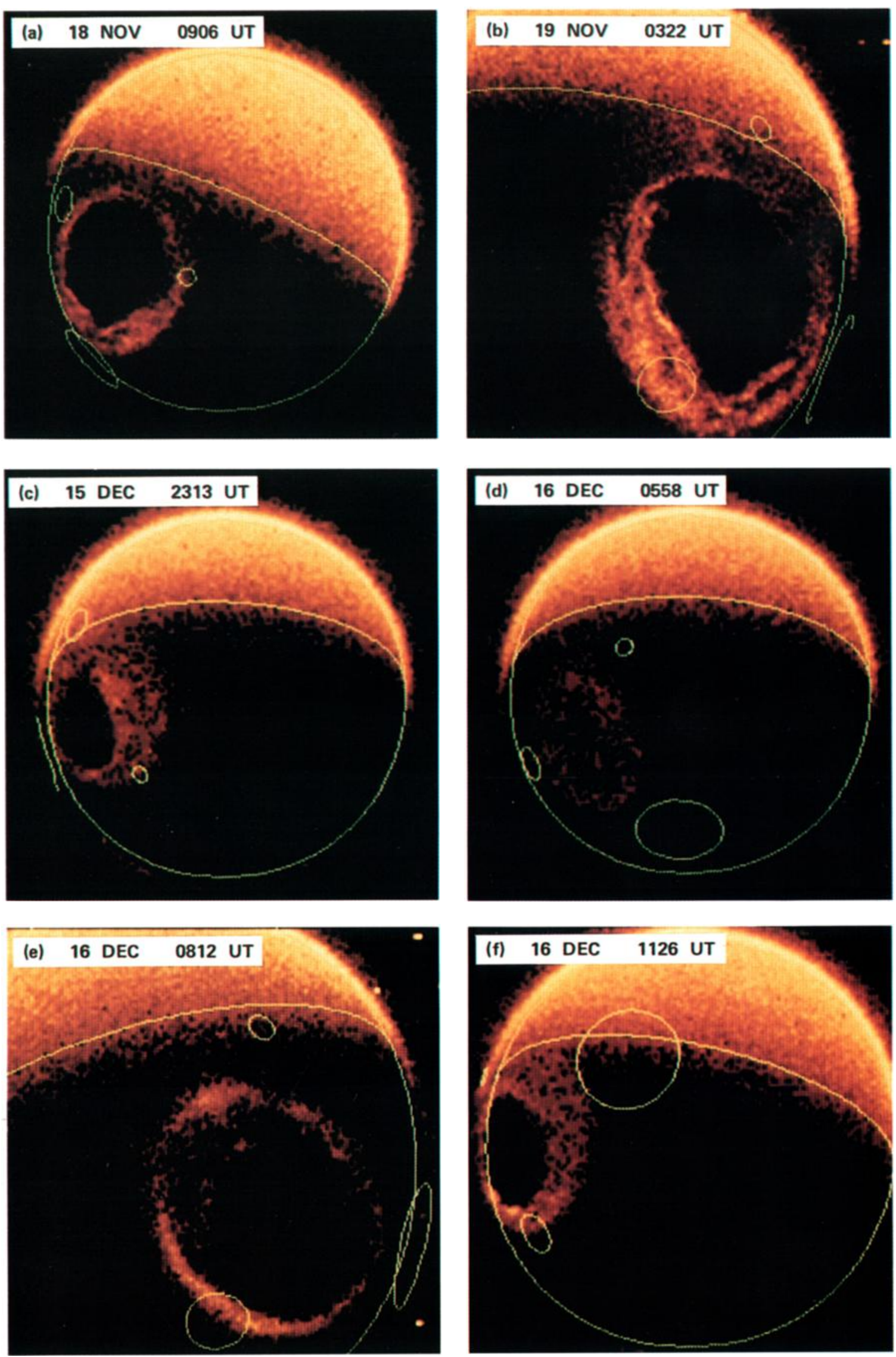

Plate 2. DE 1 images of northern polar latitudes showing the sunlit portion of the earth, and the auroral oval; the limb, the terminator ( $90^{\circ}$ solar zenith angle), and the radars' fields of view (largest for Millstone, smallest for EISCAT) are overlayed on each image. 
lower latitude than the electron particle precipitation. This was true for all the orbits considered on these days. Recent Sondrestrom incoherent-scatter radar observations have also shown that, in the noon sector, the convection pattern and the precipitation pattern are closely related [Wickwar and Kofman, 1984; Kofman and Wickwar, 1984; Robinson et al., 1984]. Therefore, it is a reasonable approximation to use the auroral oval rather than the convection pattern.

\section{Drift Times Across the Polar Cap}

Implicit in this study is the fact that the time necessary for a field tube to convect across the polar cap is short compared to the lifetime of the patches. This transit time is not obtained directly with these experiments, but it can be estimated. Because DE 2 was in a dawn-dusk orbit, the ion velocity component in the antisunward direction is roughly parallel to $\mathrm{v}_{x}$, the drift meter component perpendicular to the satellite motion. This component was quite variable with peak values of $3000 \mathrm{~m} / \mathrm{s}$, and at times with reversals to a sunward direction. The largest drifts often occurred very close to the ion convection reversal, at the equatorward edge of the polar cap. Nevertheless, over large portions of the polar cap, $v_{x}$ averaged about $500 \mathrm{~m} / \mathrm{s}(\simeq 25 \mathrm{mV} / \mathrm{m})$ as shown, for example, in Plates $3 a$ and $3 b$.

Another estimate of the average drift velocity can be obtained from the magnitude of $K p$. For $K p=3$, the polar cap potential drop is of the order of $60 \mathrm{kV}$ [Doyle and Burke, 1983], which corresponds to an average polar cap electric field of the order of 25$\mathrm{mV} / \mathrm{m}$ when the size of the polar cap is that from Gussenhoven et al. [1983]. This value is consistent with other measurements of the electric field in the polar cap [Heelis and Hanson, 1980; Weber et al. 1984], which have yielded drift speeds of 500 to $1000 \mathrm{~m} / \mathrm{s}$. Thus, a $25-\mathrm{mV} / \mathrm{m}$ average electric field seems reasonable. From this value, the transit time for plasma motion across the polar cap is about 1.5 hours. It is likely that this transit time varied with time and position, yielding a range of values of greater and lesser magnitudes.

The transit time across the polar cap has also been estimated by Kelley et al. [1982], Sojka et al. [1979, 1981], and R. M. Robinson et al. (unpublished manuscript, 1984) using magnetospheric convection models. The values given range from 1.5 to 4 hours. These values are consistent with our previous estımate.

These estımates of transit time, even the longer ones, are relatively short compared to the lifetıme of the ionization at the peak of the $F$ layer. Rishbeth and Garriott [1969] have shown that the lifetime in the $F$ region depends primarily on the decay time at the altitude of the ionization peak. We have seen in the previous section that this peak was at high altitudes $(425$ and $475 \mathrm{~km}$ on November 18,360 and $450 \mathrm{~km}$ on December 15 , for Chatanika and EISCAT, respectively). At these heights, the ionization time constants range from 9 to 90 hours, respectively, when adoptıng the value for the linear onization loss coefficient $\beta$ given by Rishbeth and Garriott [1969]. These crude estimates assume diffusive equilibrium and do not take into consideration ionization losses due to thermal plasma outflow.

In the midnight sector, the neutral wind helps to sustain the high ionization level [Schunk et al., 1976; Watkins and Richards, 1979]. On both days shown, the appearance of patches within the radar beam coincided with a southward turning of the $F$ region wind. By raisıng the peak of the $F$ layer, this wind contributed to increasing the ionization lifetime. The meridional wind was qualitatively similar at Chatanika and EISCAT but was stronger at EISCAT, a result which is consistent with the higher altitude of the ionızation peak at EISCAT. Therefore, the neutral dynamics also affects the maintenance of the ionization patches and can partly explain the observed differences in nighttime densities.

The December 15 observations are not straightforward to interpret because the activity was so low that Chatanika and EISCAT were probably south of the auroral oval during much of the experiment. This was seen on several DE 2 orbits and is apparent in some of the DE 1 auroral images (e.g., Plate $2 d$ ). However, as was mentioned, two small substorms occurred when EISCAT and then Chatanika were in the evening sector. In both cases, it was shortly after the substorm occurred that patches drifted through the EISCAT and Chatanika beams (three and two hours, respectively). Thus during the small substorms the plasma drift speed across the polar cap was probably enhanced, and the latitude of the auroral zone decreased, so that blobs could reach the latitude of EISCAT and Chatanika. This assumption was confirmed by the DE 2 data. On both occasions, the spacecraft was over the northern hemisphere at a time close to the onset of the substorms. The velocity component, which is mostly in the noon-midnight direction, reached $1000 \mathrm{~m} / \mathrm{s}(\sim 50 \mathrm{mV} / \mathrm{m})$ within the polar cap (at 1936 UT on December 15, orbit 1990; and 0824 UT on December 16, orbit 1998). The equatorward edge of the sunward convection moved down to an invariant latitude of $64.2^{\circ}$ on the dawnside and $67^{\circ}$ on the duskside. (This limit was much higher, $\sim 75^{\circ}$, when no substorm activity was taking place.)

During another MITHRAS experiment, on December 8, 1981, a similar sequence of events was observed. Although this period was not as quiet as December 15, it represents another period of relative magnetic quiescence during which intense ionization patches appeared in the EISCAT field of view after a substorm. Note that, in this case, as in the December 15-16 case, the expansion of the oval is invoked so that solar-produced ionization is added to the expanding convection pattern in the noon sector and is available to supply enhanced ionization to the polarcap. It is not the increase in particle-produced ionization that is responsible for the increase in observed electron density. If this were the case, then patches of particle-produced Ionization that would be associated with this increased substorm activity would also be seen at Millstone.

The MITHRAS data do not include observations taken during a period so quiet as to be completely devoid of substorm activity during many hours. Consequently, we cannot verify whether patches would be absent at the Tromso longitude during these nights of totally undisturbed conditions.

\section{Case of Octoher 25-26, 1981}

Interestingly, the only case when the longitudinal dependence discussed here was not as clear, is the exception that proves the rule. It occurred on October 25-26, 1981, during a period when the Chatanıka radar was operated for almost 36 consecutive hours (see Table 1). The magnetic activity was moderately high in the middle of this period and was quiet before and after. For reasons that are not clear at this point, and that may be related to this increased activity, the daytıme, solar-produced electron density was significantly smaller during the active period than before and after. The $F$ region density during noon was reduced by more than a third, at both Chatanika and Millstone. No daytime measurements were made at EISCAT during this active period. However, nighttime densities measured at EISCAT were very low compared to the other EISCAT observations. This can be explained by the fact that the plasma introduced into the polar cap near noon was significantly less dense than usual. Therefore, the absence of intense 


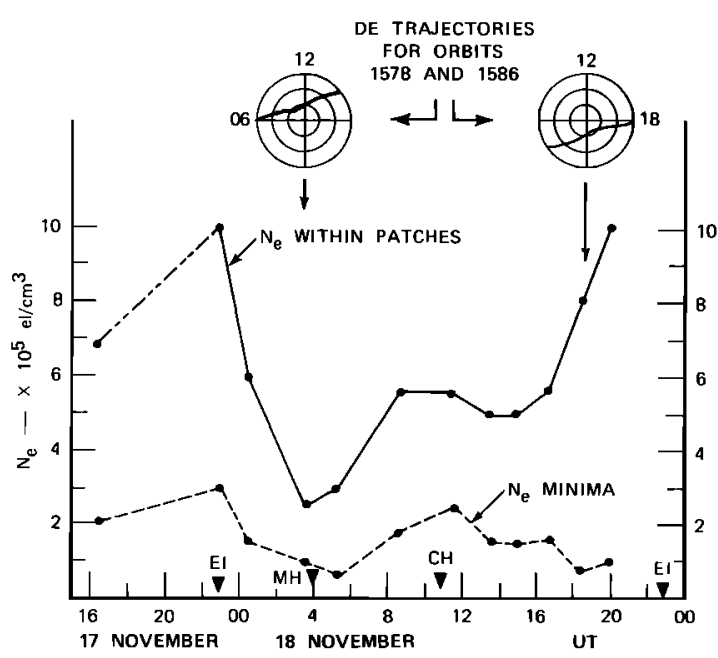

Fig. 10. Electron density measured in the polar cap by DE 2 at an altutude of $\sim 600 \mathrm{~km}$. The solıd line shows the density withın the ionization patches, while the dotted line shows the densities in the minima. The UT when each radar is at magnetic midnight is indicated along the time axis.

nighttime patches at EISCAT supports our hypothesis of plasma transport across the polar cap. This example is also consistent with the contention that these patches are not initially produced by particle precipitation.

In summary, we find that systematic longitudinal differences in the nighttime $F$ region can be explained by assuming that the observed patches are a remnant of solar produced sonization that has been convected across the polar cap. During the November 18 experiment, the geomagnetic activity was moderately perturbed and, as estımated from coincident DE 2 observations, the plasma crossed the polar cap in a relatively short time. On December 15-16, magnetic conditions were much quieter. Nevertheless, intense patches were detected at Chatanika and EISCAT. Periods of small substorm activity preceded the occurrence of the blobs. Presumably, the expansion of the auroral oval and the increase in convection speed were sufficient to "capture" and convect the patches to the Chatanika and EISCAT fields of view.

\section{Polar Cap Electron Density Measured by DE 2}

Electron density observations with DE 2 provide further support for our explanation of the UT effect. On November 18-19, 1981, the spacecraft altitude was between 450 and $750 \mathrm{~km}$ above the northern auroral zone. The scale height within the density patches was quite large, as shown by the profiles in Figures 4 and 7 . Therefore, it is not surprising that large-scale density variations were readily apparent in the DE 2 in-situ density data. The background electron density within the patches (solid line) and the density minima (dotted line) are shown as a function of UT in Figure 10. One pair of values was read from each available pass, using the DE summary plots. The values selected correspond to times when DE 2 was in the polar cap, at an altitude of $600 \pm 50$ $\mathrm{km}$. As an example, the two values that correspond to pass 1586 , at $\simeq 1820 \mathrm{UT}$, are marked A and B in Plate $3 a$. Figure 10 shows that the electron density is strongly dependent upon UT. Comparing this figure to the plot of hemispheric power input (Figure 2), it is evident that the two variations are unrelated. The maxima in the density are not correlated with the times of maximum particle precipitation. However, these variations in electron density do depend upon the relative position of the oval and the terminator.
Arrows on the tıme axis indicate magnetic midnight at each radar. As was observed from the radars, the intensity of the patches increases as the universal time progresses from the time when Millstone, then Chatanika, and then EISCAT are at magnetic midnight. The density in the minima varies by a smaller amount, and it is not clear whether it is UT modulated in a similar way. An equivalent plot for the December 15, 1981 experıment is not shown because the altitude of DE 2 was too low, below the peak of the $F$ region enhancements most of the time.

Two satellite trajectories are shown in Figure 10 in an MLT/ invariant-latitude coordinate system to illustrate a fact that could at first appear surprising: it is when the DE trajectory is the closest to the cusp that the patches have the lowest density. This is simply because, at this UT, the noon-sector auroral oval is not sunlit. Therefore, Figure 10 demonstrates that the densities show the same UT dependence as was seen in the radar data. This provides further evidence to our hypothesis.

\section{OBSERvation Summary}

In summary, coincident auroral-zone experıments were conducted using three incoherent-scatter radars at widely spaced longitudes. These observations have shown that, during the night, the $F$ layer electron density is strongly dependent on the longitude of the observing site. Ionization patches were observed in the nighttime $F$ regıon from Chatanika and EISCAT. Densities that were observed from Millstone were substantially smaller. The electron density within these maxima is larger at EISCAT than at Chatanika. This effect is not isolated to certain observing periods, but is seen in all cases of MITHRAS three-radar experiments. These densitues, when observed in the midnight sector auroral zone, had a peak density at a high altitude ( 360 to $475 \mathrm{~km}$ ). The southward neutral wind measured coincidentally was presumably a factor that helped maintain the $F$ layer at a high altitude where its lifetime is long compared to the time it takes to transit from the solar-illuminated regions. DE 2 measurements also showed a UT dependence of the electron density. The density was maximum when EISCAT was in the midnight sector (1800-2000 UT) and was minimum when Millstone was in the midnight sector (0400 UT). The DE I auroral images showed that a minimum in insolation in the auroral zone occurs at the UT when Millstone is in the midnight sector.

\section{Discussion}

It has been suggested that particle precipitation associated with the auroral regions was the main source of ionization within the blobs [Kelley et al., 1982; R. M. Robinson et al., unpublished manuscript, 1984]. The observations reported in this paper do not seem consistent with this hypothesis because it does not explain the UT dependence of the maxima in $F$ region density. Instead, as mentioned earlier, we think that these observations are explained in terms of the transport across the polar cap of the EUV-produced plasmas. This idea was suggested as early as 1964 by Sato [Sato and Rourke, 1964]. Due to the wobbling of the magnetic pole, the auroral oval insolation varies during the course of a 24-hour period. The UT when the noon portion of the auroral oval is at its lowest geographic latitude corresponds roughly to the time when the plasma drifting across the polar cap contains the largest electron densities.

The positions of Chatanika and EISCAT are not far from being symmetric about the great circle that passes through the geographic and geomagnetic north poles. However, the densities at EISCAT were substantially larger than at Chatanika. This is because 


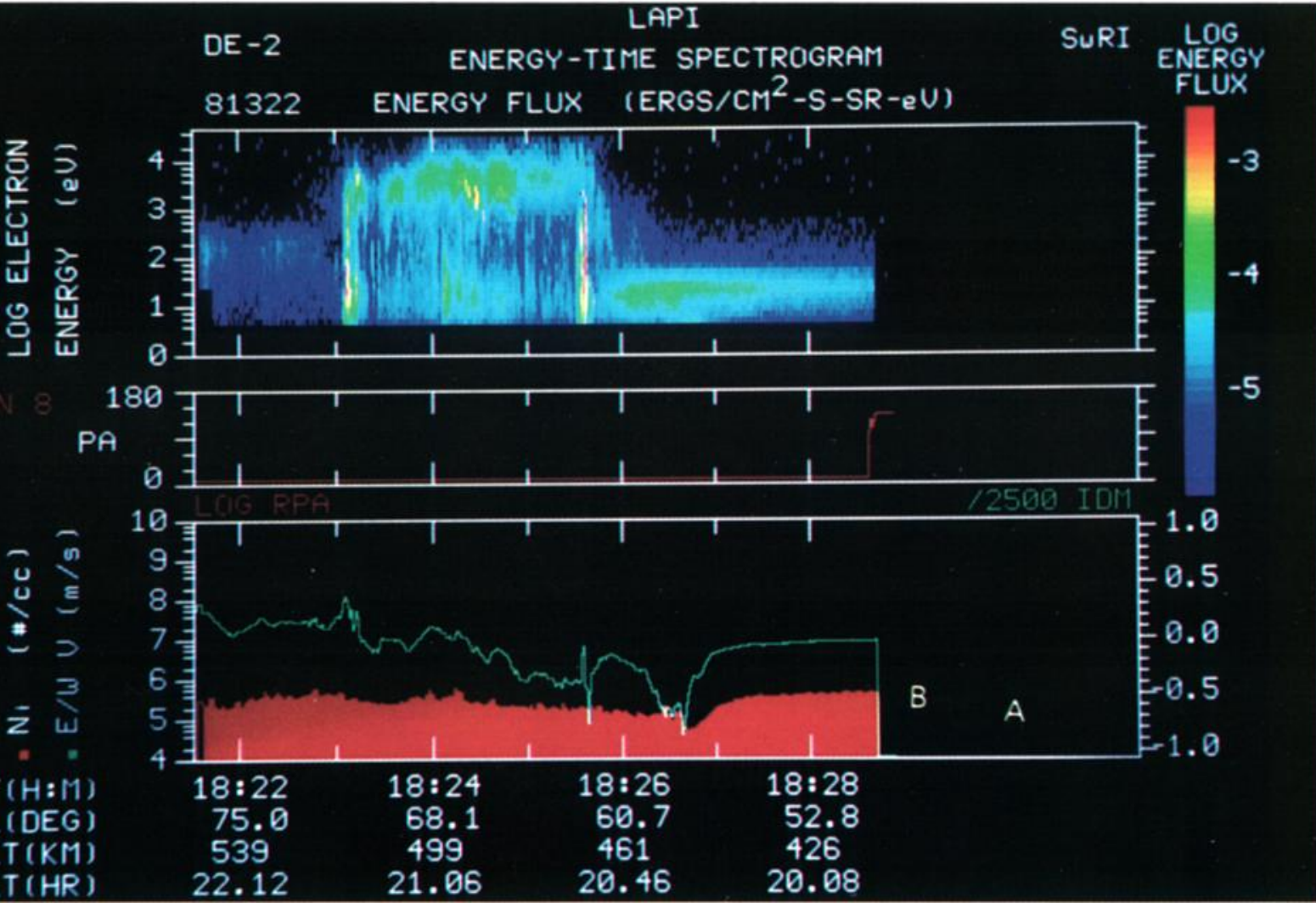

Plate 3a. DE 2 data for a dawn-dusk pass on November 18, 1981. The upper panel shows energy-time spectrograms from the LAPI instrument. The middle panel shows the pitch-angle of the LAPI detector. The lower panel shows simultaneously the electron density from the Langmuir probe (envelope of the red surface with $\log$ scale to the left) and the ion velocity (green curve with relative scale on the right labelled from -1 to +1 where $\pm I$ corresponds to $\pm 2500 \mathrm{~m} / \mathrm{s}$ ). The points $A$ and $B$ indicate the background density within the patches and the density minima, respectively (see text).

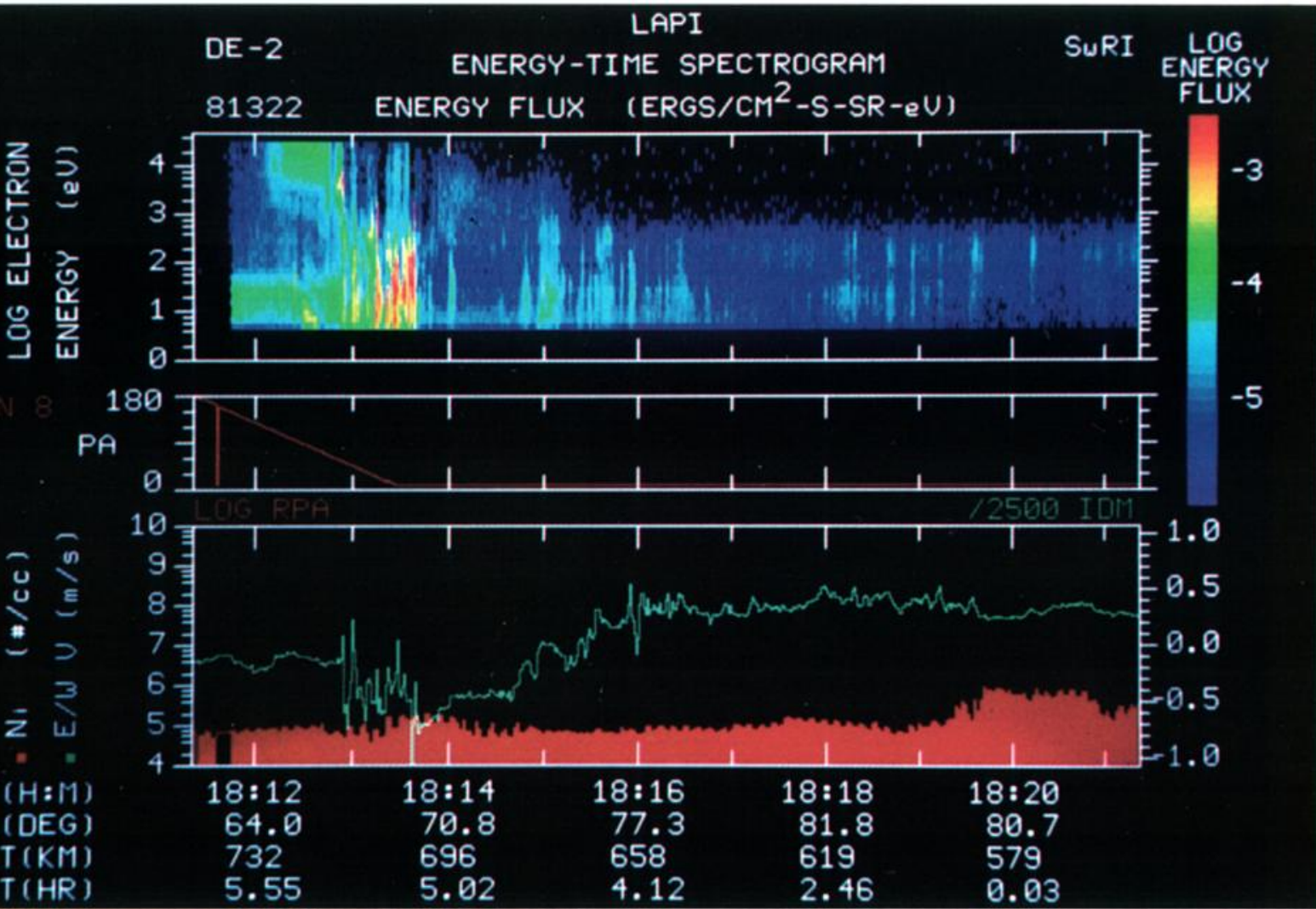

Plate 3b. Same as Plate 3a, but for second half of polar crossing, on dusk side. 
the system formed by the magnetospheric convection pattern and the earth is not symmetric. Three factors contribute to this asymmetry: (1) when a symmetric convection pattern is mapped to an inertial frame of reference the morning cell becomes larger than the afternoon cell; (2) the convection across the polar cap is shifted to early hours due to the finite conductivities (see, for example, Barbosa [1984] and Friis-Christensen et al., [1985]); (3) the statistical auroral oval is not centered at the geomagnetic pole, but is offset by $2^{\circ}$ to $5^{\circ}$ in the direction of 0240 MLT [Gussenhovenet al., 1983]; and, (4) more importantly, the time when EISCAT is in the midnight sector comes after the time of maximum insolation, whereas the time when Chatanika is in the midnight sector is before. The ionization at midnight depends on the relative position of the terminator and the auroral zone $1-3$ hours before the radar is at midnight.

However, the processes that influence the $F$ region densities are complex and numerous. They include atmospheric, ionospheric, and magnetospheric effects such as neutral wind, neutral atmospheric composition, diffusion, temperature, particle precipitation, and ionospheric plasma convection. Thus, we do not claim to have answered all possible questions in this paper. To model the UT effect properly we need to know the global convection pattern more precisely and how it varies with time. A full model of the kind produced by Schunk and Raitt $[1980]$ and Sojka et al. $[1979,1981]$ is needed in order to assess the relative importance of these effects. In fact, Sojka and Schunk [1982] have applied their model to predict what the ionospheric densities would be at the three radar's meridians. Their paper covers two seasons and all latitudes north of $45^{\circ}$. The calculations for winter season were conducted for a level of magnetic activity that is similar to the November 18 experiment. However, the simulation was done for solar minimum conditions. The noon densities were $\sim 4 \times 10^{5} \mathrm{el} / \mathrm{cm}^{3}$, a factor of three smaller than the measured densities. Their calculated densities were displayed at $300 \mathrm{~km}$ height (their Figure 1). At Millstone and Chatanika, the predictions at magnetic midnight give almost the same value $\left(\simeq 2.8 \times 10^{5} \mathrm{el} / \mathrm{cm}^{3}\right)$ while at EISCAT the density is larger $\left(5.6 \times 10^{5}\right)$. In Figures 4 and 7 of this paper we have marked the model values. These predictions are in fairly good agreement with the data. However, a conclusive comparison is difficult because their model was for solar cycle minimum, and because their plot was for an altitude below the $F$ region peak. A comparison between the data and the model at higher altitudes would be very useful.

Another comparison concerns the electron density in the polar cap. Sojka and Schunk [1982] displayed their model prediction versus height and latitude for the three UT's that correspond to 1800 MLT for each radar site (their Figure 4). The predicted polar cap densities are lowest at $0400 \mathrm{UT}$, and thus the model is in good qualitative agreement with the observations.

The DE 2 Langmuir probe data (Figure 10) have illustrated for a one-day period how the electron densities in the polar cap exhibit a maximum around 1800-2000 UT. The same UT effect has been observed using a large body of ionosonde data collected in the two polar regions during the International Geophysical Year. Duncan [1962] reported that a maximum occurs in the Antarctic around $0600 \mathrm{UT}$, and in the Arctic around 1800; these maxima are about 12 hours apart. In fact, $1800 \mathrm{UT}$ is close to the time when the geographic latitude of the auroral oval, on the dayside, is the lowest (Figure $9 d$ ). As reported by Pike [1971], and as can be deduced by looking at the maps in Figures 1 and $9 d$, it is at the longitudes of western Siberia that the nighttime $F$ region is the largest, and at the longitudes of the east coast of Canada and of the United States that the nighttime density is the lowest.
This UT effect should show up in the background intensity at $6300 \mathrm{~A}$. Under quiet conditions, most of this emission will arise from dissociative recombination, which is proportional to electron density. This UT dependence should also affect HF propagation and VHF transionospheric propagation at high latitudes. Because these patches are associated with ionospheric scintillation [Vickrey et al., 1980; Rino, 1982; Weber et al., 1984], there should be a strong longitudinal dependence in nighttime scintillation. As stated by Basu [1975], little is known about the longitudinal dependence in auroral scintillation models. However, based on observations from only two sites, Basu [1975] did see evidence for this UT effect. The HILAT experiment should provide a better data set to verify our prediction that ionospheric scintillation is UT dependent at high latitudes.

Acknowledgmemts. Research with the Chatanika and Millstone Hill facilities was supported by Air Force Office of Scientific Research contracts F49620-81-C-0042 and F49620-83-K-0005, by National Science Foundation grants ATM 81-17792 and ATM 78-23658, and by Air Force Office of Scientific Research grant 83-0002 to Massachusetts Institute of Technology. EISCAT is supported by the Suomen Akatemia (Finland), the Centre National de la Recherche Scientifique (France), the Max Planck Gesellschaft (West Germany), the Norges Almenvitenskaplige Forskningsraad (Norway), the Naturvetenskapliga Forskningsroadet (Sweden), and the Science Research Council (United Kingdom). Research at the University of Iowa was supported in part by the National Aeronautics and Space Administration under contract NAS5-25689 and grant NGL 16-001-002 and by the Office of Naval Research under grant N00014-76-C-0016. The work at NOAA was supported by NSF grant ATM 81-19477, at Southwest Research Institute by NASA contract NAS5-26363 and Air Force Geophysics Laboratory contract FY 712184 N000 6, and at University of Texas at Dallas by NASA grant NAG5-305 and NAG5-306. We are thankful to $J$. P. Berchem, E. J. Smith, and C. T. Russell who provided the ISEE data.

The editor thanks J. J. Sojka and W. C. Knudsen for their assistance in evaluating this paper.

\section{REFERENCES}

Barbosa, D. D., An energy principle for high-latitude electrodynamics, $J$. Geophys. Res., 89, $2881,1984$.

Basu, S., Universal time seasonal variations of auroral zone magnetic activity and VHF scintillations, J. Geophys. Res., 80, 4725, 1975.

Caudal, G., O. de la Beaujardière, D. Alcayde, J. Holt, and G. Lejeune, Simultaneous measurements of the electrodynamic parameters of the auroral ionosphere by the EISCAT, Chatanika and Millstone Hill radars, Ann. Geophys., Gauthier Villars, 2, 369, 1984.

de la Beaujardière, O., M. Baron, V. B. Wickwar, C. Senior, and J. V. Evans, MITHRAS: A program of simultaneous radar observations of the high-latitude auroral zone, SRI Project 3261 final report, contract F49620-81-C-0042, Dep. of the Air Force, Bolling Air Force Base, Washington, D. C., 1982.

de la Beaujardière, O., et al., MITHRAS: A brief description, Radio Sci., $19,605,1984$.

Doyle, M. A., and W. J. Burke, S3-2 measurements of the polar cap potential, J. Geophys. Res., 88, 9125, 1983.

Duncan, R. A., Universal time control of the arctic and antarctic $F$ region, J. Geophys. Res., 67, 1823, 1962.

Evans, J. V., J. M. Holt, and R. H. Wand, Millstone Hill incoherent scatter observations of auroral convection over $60^{\circ}<\Lambda<75^{\circ}$, 1. Observing and data reduction procedures, J. Geophys. Res., 84, 7059, 1979.

Folkestad, K., T. Hagfors, and S. Westerlund, ElSCAT: An updated description of technical characteristics and operational capabilities, Radio Sci., 18, 867, 1983.

Foster, J. C., lonospheric signatures of magnetospheric convection, $J$. Geophys. Res., 89, 855, 1984.

Frank, L. A., J. D. Craven, K. L. Ackerson, M. R. English, R. H. Eather, and R. L. Carovillano, Global auroral imaging instrumentation for the dynamics explorer mission, Space Sci. Instrum., 5, 369, 1981.

Friis-Christensen, E., Y. Kamide, A. D. Richmond, and S. Matsushita, Interplanetary magnetic field control of high-latitude electric fields and currents determined from Greenland magnetometer data, J. Geophys. Res., 90, 1325, 1985. 
Gussenhoven, M. S , D. A. Hardy, and W. J. Burke, DMSP/F2 electron observations of equatorward auroral boundaries and their relationship to magnetospheric electric lields, J. Geophys. Res., 86, 768, 1981.

Gussenhoven, M. S., D. A Hardy, and N. Heınemann, Systematics of the equatorward diffuse auroral boundary, J. Geophys. Res., 88, 5692, 1983.

Heelis, R. A., and W. B. Hanson, High latitude ion convection in the nighttime $F$ regıon, $J$ Geophys. Res , 85, 1995, 1980

Heelıs, R. A., J. D. Winningham, and W. B. Hanson, The relationshıps between high-latitude convection reversals and the energetic particle morphology observed by Atmosphere Explorer, J. Geophys. Res., 85, 3315,1980

Heelis, R. A., W. B. Hanson, C. R. Lippincott, D R Zuccaro, L. H. Harmon, B. J. Holt, J. E. Doherty, and R. A. Power, The ion drift meter for Dynamics Explorer-B, Space Sc. Instrum., 5, 51 I, 1981.

Hill, V. J., D. S. Evans, and W. M. Retallak, A near real-time computer display showing the geographic location and intensity of auroral precipitatıon using TIROS/NOAA satellıte observatıons, Eos Trans. AGU $63,1052,1982$

Hoffman, R A., and E. R Schmerling, Dynamics Explorer Program: An overview, Space Sci. Instrum , 5, 345, 1981.

Kelley, M. C., J. F. Vickrey, C. W. Carlson, and R. Torbert, On the origin and spatial extent of high latıtude $F$ region irregularities, $J$. Geophys. Res., 87, 4469, 1982.

Kelly, J. D., and J. F Vickrey, $F$ region 1onospherıc structure associated with antisunward flow near the dayside polar cusp, Geophys. Res. Lett., $/ 1,907,1984$.

Knudsen, W. C., Magnetospheric convection and the high-latitude $F_{2}$ ionosphere, J. Geophys. Res., 79, 1046, 1974.

Knudsen, W. C., P. M. Banks, J D. Winningham, and D. M. Klumpar, Numerical model of the convecting $F_{2}$ ionosphere at high latitudes, $J$. Geophys. Res., 82, 4784, 1977.

Kofman, W., and V. B. Wickwar, Very high electron temperatures in the daytime $F$ region at Sondrestrom, Geophys. Res. Lett., II, 919, 1984

Krehbiel, J P., L. H. Brace, R. F. Their, W. H. Pınkus, and R. B. Kaplan, The Dynamics Explorer Langmuir probe instrument, Space Sci. Instrum., 493, 1981

Leadabrand, R. L., M. J. Baron, J. Petriceks, and H. F. Bates, Chatanıa Alaska, auroral-zone incoherent-scatter facilty, Radıo Scı., 7, 747, 1972.

Mantas, G. P., and J. C. G Walker, The penetration of soft electrons into the ionosphere, Planet. Space Sci, 24, 409, 1976.

Pike, C. P., A comparison of the north and south polar $F$ layers, $J$ Geophys. Res., 76, 6875, 1971.

Rino, C. L., On the application of phase screen models to interpretation of ionospheric scintillation data, Radıo Sct., 17, 855, 1982

Rishbeth, H., and O. K Garriott, Introduction to lonospheric Physics, Academic, New York, 1969.

Robınson, R. M., D. S. Evans, T. A. Potemra, and J. D. Kelly, Radar and satellite measurements of an $F$ region ionization enhancement in the post-noon sector, Geophys. Res Letl., II, 899, 1984.

Roble, R. G., and M. H. Rees, Time-dependent studies of the aurora Effects of particle precipitation on the dynamic morphology of ionospheric and atmospheric properties, Planet. Space Scl., 25, 991, 1977.

Sato, T., and G. F. Rourke, $F$ region enhancements in the Antarctic, $J$ Geophys. Res., 69, 4591, 1964

Schunk, R. W., and W. J. Raitt, Atomic nitrogen and oxygen ions in the daytume high-latitude $F$ region, $J$. Geophys. Res., 85, 1255, 1980.

Schunk, R. W., and J. J. Sojka, Ion temperature varıations in the daytıme high-latitude $F$ region, $J$. Geophys Res., 87, 5169, 1982.

Schunk, R. W., P. M. Banks, and W. J. Ratt, Effects of electric fields and other processes upon the nighttime high-latıtude $F$ layer, J. Geophys. Res., 81, 3271, 1976.

Sojka, J. J , and R. W. Schunk, Predicted durnal variations of electron density for three high-latitude incoherent scatter radars, Geophys. Res. Letl., 9, 143, 1982.

Sojka, J. J., W. J. Raitt, and R. W. Schunk, Effect of displaced geomagnetic and geographic poles on high-latitude plasma convection and ionospheric depletions, J. Geophys. Res., 84, 5943, 1979.

Sojka, J. J., W. J. Raitt, and R. W. Schunk, A theoretical study of the hıgh-latıtude winter $F$ region at solar minımum for low magnetıc activity, J. Geophys. Res., 86, 609, [981.

Sojka, J. J., W. J. Raitt, and R. W. Schunk, Observations of the diurnal dependence of the high-latitude $F$ region ion density by DMSP satellites, J. Geophys. Res., 87, 1711, 1982.

Torbert, R. B., C. A. Cattell, F. S. Mozer, and C.-I. Meng, The boundary of the polar cap and its relation to electric lields, field-aligned currents, and auroral particle precipitation, in Physics of Auroral Arc FormaIIon, Geophys. Monogr. Ser, vol. 25, edited by S.-I. Akasofu and J. R. Kan, p. 143, AGU, Washıngton, D. C., 1981.

Vickrey, J. F., C. L. Rino, and R. A. Potemra, Chatanka TRIAD observations of unstable ionization enhancements in the auroral F region, Geophys. Res. Lett, 7, 789, 1980.

Watkıns, B. J., A numerical computer investigation of the polar $F$ region Ionosphere, Planet. Space $\mathrm{Sct}, 26,599,1978$.

Watkins, B. J., and P G. Richards, A theoretıcal investıgation of the role of neutral winds and particle precipitation in the formation of the auroral $F$ region ionosphere, J, Atmos. Terr. Phys., 4I, 179, 1979.

Weber, E. J., J. Buchau, J. G. Moore, J. R. Sharber, R. C. Livingston, J. D. Winningham, and B. W. Reınisch, $F$ layer ionization patches in the polar cap, J. Geophys. Res., 89, 1683, 1984.

Wickwar, V. B., and W. Kofman, Dayside red auroras at very high latitudes: The importance of thermal excitation, Geophys. Res. Lett., $11,923,1984$

Winnıngham, J. D., J. L. Burch, N Eaker, V. A. Blevıns, and R. A. Hoffman, The low altitude plasma instrument (LAPI), Space Scl. Instrum., 101, 465, 1981

L. H. Brace, National Aeronautics and Space Administration, Greenbelt, MD 2077I

G. Caudal, Centre de Recherches sur la Physıque de l'Environnement, 4 Avenue de Neptune, 94107 Saint-Maur Cedex, France. J. D. Craven and L. a. Frank, University of Iowa, lowa City, IA $\mathbf{5 2 2 4 2 .}$

O. de la Beaujardıere and V. B. Wickwar, SRI International, 333 Ravenswood Avenue, Menlo Park, CA 94025.

D. S. Evans, National Oceanic and Atmospheric Admintstration, Boulder, CO 80303 .

R. A. Heelıs, Unıversity of Texas at Dallas, Richardson, TX 75080.

J. M. Holt, Haystack Observatory, Westford, MA 01886.

J. D. Winningham, Southwest Research Instıtute, P O. Drawer 28510. San Antonio, TX 78284

(Recelved August 231984 revised December 18, 1984 accepted January 10, 1985.) 